\title{
Peertechz
}

Research Article

\section{Delayed percutaneous} endoscopic gastrostomy tube removal in patients with oropharyngeal carcinoma

\section{John T Lucas ${ }^{1}$, Rita Poon², Scott Finlay ${ }^{3}$, Ryan Anderson ${ }^{4}$, Mac Robinson ${ }^{5}$, Ralph D’Agostino ${ }^{6}$, Kathryn M Greven ${ }^{1}$ and Mercedes Porosnicu7*}

${ }^{1}$ Department of Radiation Oncology, Wake Forest Baptist Medical Center, Winston-Salem, NC 27157, United States

${ }^{2}$ Section of Hospital Medicine, Wake Forest Baptist Medical Center, Winston-Salem, NC 27517, United States

${ }^{3}$ Department of Otolaryngology, Boston Medical Center, Boston, MA 02118, United States ${ }^{4}$ Wake Forest School of Medicine, Winston-Salem, NC 27157, United States ${ }^{5}$ Comprehensive Cancer Center, Wake Forest Baptist Medical Center, Winston-Salem, NC 27157, United States

${ }^{6}$ Department of Biostatistical Sciences, Wake Forest Baptist Medical Center, Winston-Salem, NC 27517 United States

${ }^{7}$ Department of Internal Medicine-Hematology and Oncology, Wake Forest Baptist Medical Center, Winston-Salem, NC 27517, United States
Received: 14 September, 2020

Accepted: 19 October, 2020

Published: 20 October, 2020

*Corresponding author: Mercedes Porosnicu, MD, Department of Internal Medicine-Hematology and Oncology, Wake Forest Baptist Medical Center, Winston-Salem, NC 27517, United States, Tel: 336716-8664; E-mail:mporosni@wakehealth.edu

Keywords: Head and neck neoplasms; Oropharyngea neoplasms; Radiation; Nutritional support;

Gastrostomy; Enteral nutrition; Mucositis; Respiratory aspiration; Weight loss

https://www.peertechz.com

\section{Check for updates}

\footnotetext{
Abstract

Objective: Early nutritional intervention through enteral feeding can reduce treatment alterations and complications in patients with Oropharyngeal Cancer (OPC) undergoing Chemoradiation Treatment (CRT). There is no conclusive evidence supporting prophylactic (pPEG) versus reactive PEG. Prolonged PEG dependence is a concerning adverse effect of pPEG. Recognition of risk factors for pPEG can trigger early interventions to prevent prolonged dependence. This study aims to identify the risk factors for prolonged pPEG dependence in a sample of oropharyngeal cancer patient population treated with concurrent chemoradiotherapy at our institution.

Methods: This is a retrospective analysis of 75 OPC patients with definitive CRT and pPEG tube placement at our institution. The relationships between potential predictors and time to PPEG tube removal were evaluated using Cox proportional hazards univariate and multivariate modeling

Results: Prophylactic PEG tube use at one year was $15.1 \%$ based on estimates from the Kaplan-Meier curve. After adjusting for patient- and treatment- factors, mucositis grade and advanced cancer stage remained significant predictors of delayed pPEG tube removal in the multivariate model.

Conclusion: High grade mucositis, tumor location, and advanced cancer stage contribute to delayed pPEG tube removal, but these characteristics may also place patients at highest risk for reactive PEG tube placement. Although this study is limited in size and design, it describes the characteristics of a population with pPEG placement, as well as factors for delayed PEG tube removal.
} 


\section{Introduction}

Over $60 \%$ of patients with Oropharyngeal Cancer (OPC) present with advanced disease, $40 \%$ of whom are nutritionally compromised at diagnosis [1]. Patients with OPC are at risk for malnutrition secondary to cancer-related cachexia, concomitant smoking and alcohol abuse, and inherent anatomical factors precluding normal swallowing function $[2,3]$. Because of involving base of tongue, locally advanced OPC often requires concurrent Chemotherapy and Radiotherapy (CRT) on primary tumor and bilateral neck. Such intensive regimen worsens significantly the nutritional imbalance via treatment-related mucositis, esophagitis, odynophagia, xerostomia and dysgeusia [4-7]. Significant weight loss during and after treatment is a major risk factor for treatment interruptions, hospital admissions and infections [6]. Accordingly, these nutritional deficiencies have been identified as adverse prognostic factors in oncologic outcomes, including reduced treatment response and increased cancer recurrence [8] as well as negatively influencing overall survival [9].

Retrospective studies have concluded that early nutritional intervention via inserting prophylactic percutaneous endoscopic gastrostomy (pPEG) tubes before CRT initiation improves weight and nutrition metrics, reducing treatmentrelated complications and this may result in reduced treatment interruptions and hospitalizations $[4,5,10,11]$. However, there has been concern that PPEG may contribute to increased risk of late swallowing dysfunction, due to PEG reliance, causing secondary disuse atrophy of swallow muscles [12]. Prolonged dependence remains the most concerning adverse effect of PEG tube placement. It has been shown that poor performance status, pre-treatment dysphagia, and chemotherapy administration, were significantly associated with increased PEG dependence [13]. In a recently published large multicenter study, both practices of prophylactic and reactive PEG tubes were evaluated [14]. Patients who received accelerated radiation therapy were less likely to be PEG tube dependent at 1 year. Factors that were significantly associated with PEG tube dependence included advanced age $>50$ years, increased smoking packing years, $\mathrm{N}$ stage, and concurrent cytotoxic chemotherapy administration. In this study, prophylactic PEG tube placement was not predictive of 1year PEG-tube dependence [14]. In high performance status patients, gabapentin use was associated with decreased PEG tube dependence, suggesting that gabapentin may be used for prophylactic pain management to improve swallow muscle use and decrease atrophy. Factors that influence pPEG tube dependence. especially in specific head and neck cancer patient populations with high risk of intensive mucositis and nutrition alterations through the treatment, such as patient with oropharyngeal cancer, should be further identified and reported. Recognition of such characteristics could lead to development of early interventions that can reduce $P E G$ tube dependence.

The goal of this retrospective, single-institution study, on patients with oropharynx cancer treated with CRT, and who had pPEG placement for nutritional support, is to evaluate the incidence of delayed tube removal and to identify the characteristics that may be associated with prolonged PEG dependence.

\section{Materials and methods}

\section{Study population}

This is a single institution retrospective study approved by the Institutional Review Board. Consecutive patients with OPC treated with definitive concurrent CRT regimens over five years were identified within the Cancer Registry. Patients treated adjuvantly, treated at other hospitals, or with less than three months of follow-up were excluded. Per institutional practice, PEG tube placement was recommended prophylactically for all patients with OPC for whom CRT was planned. Only patients who had pPEG tubes placed before the beginning of CRT or within the first 3 weeks of CRT were included in this study. Patients' electronic medical records were reviewed to capture data on the outcome variable and covariates of interest.

\section{Outcome variable}

The outcome variable was time to pPEG tube removal (days). To address the primary endpoint, duration of feeding tube usage, including duration after the end of 6-week chemoradiation therapy and failure to remove the feeding tube at last follow-up, was documented. Continued use of pPEG tube from the time of treatment completion until removal was defined as the time period of dependence and was assessed at 1-2 month intervals for the first year following therapy and every 3 months thereafter.

\section{Covariates of interest}

Patient characteristics considered included the following: Age at diagnosis; sex; race (White, African American); cancer site (tongue base, tonsil, unknown primary); T stage, $\mathrm{N}$ stage; M stage; TNM stage (III, IVA, IVB, IVC); human papilloma virus (HPV) status; alcohol use; smoking status; and pPEG tube placement (before CRT, within 3 weeks of CRT). HPV status was defined based on polymerase chain reaction (PCR) testing in al but two cases $[15,16]$. Patients were considered former smokers if they had more than a ten pack-year history and had quit less than one year before diagnosis.

Treatment characteristics included: Radiotherapy dose (Gy), number of fractions, chemotherapy use (Definitive CRT, induction chemotherapy followed by CRT) and type (cisplatin, carboplatin and paclitaxel, cisplatin and cetuximab, docetaxel), RT Technique (3DCRT, IMRT), and treatment duration (number of days). Total treatment doses and oral cavity/oropharynx maximum and mean doses were recorded.

Nutrition and swallowing function parameters included: pPEG tube removed prior to last follow-up (yes, no), highest grade of mucositis (grades 1-2 vs 3-4), and presence of excessive mucus production during and immediately after treatment (yes, no). Dysphagia was assessed by referral for swallowing evaluation (yes, no), vallecula penetration (yes, no), substance penetration by flexible endoscopic evaluation of swallowing (FEES) (yes, no), documented aspiration (yes, no), 
treatment received for dysphagia (yes, no) during the followup period, and patients' ability to take oral nutrition at the end of treatment (yes, no). Hospitalization (yes, no) and weight change (lbs) were documented. Serial body weight, BMI, the Geriatric Nutritional Risk Index (GNRI) and albumin at the initiation and completion of treatment, and 3, 6 months posttreatment were also recorded. Aspiration was defined based on diagnosis from a swallowing study, laryngeal penetration by FEES, or sequelae of aspiration on chest CT. Mucositis was graded using the Common Terminology Criteria for Adverse Events v3.0 (CTCAE). GNRI has been defined previously (GNRI $=[1.489 \times$ albumin $(\mathrm{g} / \mathrm{L})]+[41.7$ (weight/ideal weight by Lorentz equation)]) [17].

\section{Statistical analysis}

Descriptive statistics were calculated for variables of interest. Continuous measures were described using the median and interquartile range and assessed for differences across groups using the Wilcoxon signed rank test. Categorical variables were described using frequencies and assessed for homogeneity using Fisher's exact and chi-square tests. A univariate Cox proportional hazards analysis was employed to estimate the influence of each covariate on time to PPEG tube removal. A multivariate logistic regression model was fit to determine the relative contribution of patient-related factors in predicting time to PPEG tube removal. Covariates were selected for consideration in the multivariate model if their $\mathrm{p}$-value was less than 0.2 in univariate analysis and if they met Cox proportional hazards model assumptions. All possible two-way interactions were tested for variables that met these criteria and those with interactions were excluded. Final selection employed backwards stepwise regression with variables retained if their p-value was less than 0.05 or if a prior knowledge supported their inclusion. All statistical tests were performed using 2-sided tests, and all analyses were performed in SAS, version 9.2 (SAS Institute, Inc.).

\section{Results}

75 patients were included in the study. The patient and treatment-related characteristics are detailed in Table 1. Approximately $90.7 \%$ of the study population received pPEG tube placement before treatment, with only $9.3 \%$ having PPEG tube placement within 3 weeks of starting treatment. The 3, 6 month, and 1 year pPEG tube dependence rates were 59.2\%, $35.5 \%$, and $15.1 \%$ respectively, with only seven patients having persistent pPEG tubes at death or last follow-up.

\section{Treatment characteristics}

All patients received CRT. Ten patients (13.3\%) received induction chemotherapy with docetaxel, cisplatin, and 5-fluorouracil before definitive RT and chemotherapy. The radio-sensitizing chemotherapy regimens included cisplatin (72\%); cisplatin and cetuximab (according to Radiation Therapy Oncology Group [RTOG] 0522 [NCTO0265941]) (4\%); weekly carboplatin and paclitaxel (8\%); and docetaxel $(2.7 \%)$ (due to advanced renal failure). Sixty-one patients $(81.3 \%)$ received radiotherapy with an IMRT technique. The median duration of CRT was 49 days (IQR 49 to 51) (Table 1) Figure 1.
Table 1: Patient and Treatment Characteristics.

\begin{tabular}{|c|c|c|c|}
\hline & & $\mathbf{N}^{1}$ & $\mathrm{M}^{2}\left(\mathrm{IQR}^{3}\right) / \%$ \\
\hline Age & years & 75 & $57(51-65)$ \\
\hline \multirow[t]{2}{*}{ Sex } & Female & 12 & 16.0 \\
\hline & Male & 63 & 84.0 \\
\hline \multirow[t]{2}{*}{ Race } & White & 65 & 85.5 \\
\hline & African American & 11 & 14.5 \\
\hline \multirow[t]{3}{*}{ Site } & Base of Tongue & 25 & 33.3 \\
\hline & Tonsil & 47 & 62.6 \\
\hline & Unknown Primary & 3 & 4.0 \\
\hline \multirow[t]{5}{*}{ T Stage } & Tx & 3 & 4.0 \\
\hline & T1 & 20 & 26.7 \\
\hline & T2 & 27 & 36.0 \\
\hline & T3 & 11 & 14.7 \\
\hline & $\mathrm{T} 4$ & 14 & 18.7 \\
\hline \multirow[t]{6}{*}{ N Stage } & NO & 3 & 4.0 \\
\hline & N1 & 8 & 10.7 \\
\hline & $\mathrm{N} 2 \mathrm{a}$ & 2 & 2.6 \\
\hline & $\mathrm{N} 2 \mathrm{~b}$ & 30 & 40.0 \\
\hline & $\mathrm{N} 2 \mathrm{c}$ & 27 & 36.0 \\
\hline & N3 & 5 & 6.7 \\
\hline \multirow[t]{2}{*}{ M Stage } & MO & 72 & 96.0 \\
\hline & M1 & 3 & 4.0 \\
\hline \multirow[t]{4}{*}{ TNM Stage } & III & 8 & 10.7 \\
\hline & IVA & 57 & 76.0 \\
\hline & IVB & 7 & 9.3 \\
\hline & IVC & 3 & 4.0 \\
\hline \multirow[t]{2}{*}{ HPV Status } & Negative & 18 & 24.0 \\
\hline & Positive & 57 & 76.0 \\
\hline \multirow[t]{2}{*}{ Alcohol Use } & Active & 28 & 37.8 \\
\hline & Occasional/Never & 46 & 62.2 \\
\hline \multirow[t]{2}{*}{ Smoking Status } & Never & 44 & 58.7 \\
\hline & Active/Former & 31 & 41.3 \\
\hline \multirow[t]{2}{*}{ pPEG Tube Placement } & Before CRT & 68 & 90.7 \\
\hline & Within 3 weeks of CRT & 7 & 9.3 \\
\hline \multirow[t]{2}{*}{ Radiotherapy } & Dose $\left(G y^{4}\right)$ & 75 & $70(70-70)$ \\
\hline & Fractions & 75 & $35(35-35)$ \\
\hline \multirow[t]{4}{*}{ Chemotherapy } & Definitive $\mathrm{CRT}^{5}$ & 65 & 86.7 \\
\hline & Cisplatin & 54 & 72.0 \\
\hline & Other ${ }^{8}$ & 11 & 14.7 \\
\hline & Induction to Definitive CRT & 10 & 13.3 \\
\hline \multirow[t]{2}{*}{ RT Technique } & $3 \mathrm{DCRT}^{6}$ & 14 & 18.7 \\
\hline & $\mathrm{IMRT}^{7}$ & 61 & 81.3 \\
\hline CRT Duration & days & 75 & $49(49-51)$ \\
\hline
\end{tabular}

${ }^{1}$ Number of patients, ${ }^{2}$ Median, ${ }^{3}$ Interquartile range, ${ }^{4}$ Gray, ${ }^{5}$ Chemotherapy and radiation therapy, ${ }^{6} \mathrm{Three}$-dimensional conformal radiotherapy, ${ }^{7}$ Intensity modulated radiotherapy, ${ }^{8}$ Carboplatin and paclitaxel, Cisplatin \& Cetuximab, Docetaxel 


\section{Nutrition and swallowing function}

The median time to tube removal was 122 days (95\% CI 61-228) (Figure 1). The pPEG tube was removed in $90.7 \%$ of patients by study completion (Table 2). Persistent pPEG tubes was due to death from progressive disease ( 5 patients), and

\section{Time to pPEG Removal}

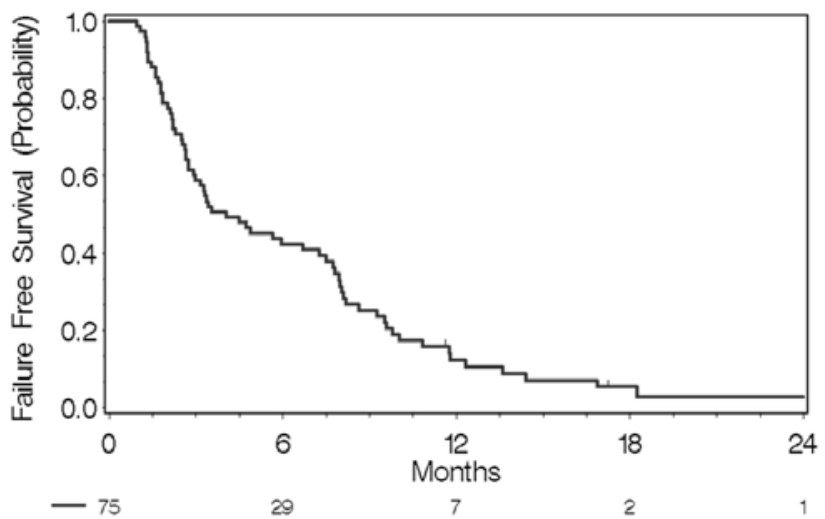

Figure 1: Time to pPEG Tube Removal.

A Kaplan Meier curve illustrating the probability (y-axis) of removal of pPEG tube over time in months (x-axis). Below the time on the $x$-axis indicates the number of individuals remaining with $\mathrm{pPEG}$ tube placement.

Table 2: Swallowing Function, Interventions and Outcomes.

\begin{tabular}{|c|c|c|c|}
\hline & & $\mathbf{N}^{1}$ & $\begin{array}{l}\mathrm{M}^{2}\left(\mathrm{IQR}^{3}\right) / \\
\text { Column \% }\end{array}$ \\
\hline \multirow[t]{2}{*}{$\begin{array}{l}\text { pPEG tube removed prior to last follow } \\
\text { up }\end{array}$} & No & 7 & 9.3 \\
\hline & Yes & 67 & 90.7 \\
\hline \multicolumn{2}{|l|}{ Time to Removal (days) } & 75 & $122.0(61.0-228.0)$ \\
\hline \multirow[t]{2}{*}{ Mucositis Grade } & Grade 1-2 & 36 & 47.3 \\
\hline & Grade 3-4 & 39 & 52.7 \\
\hline \multirow[t]{2}{*}{ Excessive Mucous Production } & No & 19 & 25.0 \\
\hline & Yes & 56 & 75.0 \\
\hline \multirow[t]{2}{*}{ Swallowing Evaluation ${ }^{4}$} & No & 23 & 30.3 \\
\hline & Yes & 52 & 69.7 \\
\hline \multirow[t]{2}{*}{ Vallecula Penetration } & Absent & 49 & 65.8 \\
\hline & Present & 26 & 34.2 \\
\hline \multirow[t]{2}{*}{ Aspiration ${ }^{4}$} & No & 31 & 40.8 \\
\hline & Yes & 44 & 59.2 \\
\hline \multirow[t]{2}{*}{ Received Dysphagia Treatment } & No & 29 & 38.2 \\
\hline & Yes & 46 & 61.8 \\
\hline \multirow[t]{2}{*}{ Oral Intake at Treatment Completion } & No & 26 & 34.7 \\
\hline & Yes & 48 & 65.3 \\
\hline \multirow[t]{2}{*}{ Hospitalization $^{4}$} & No & 53 & 72.0 \\
\hline & Yes & 21 & 28.0 \\
\hline Weight Change ${ }^{4}$ & lbs & 73 & $-4.95(-10.2-0.50)$ \\
\hline GNRI $^{5}$ Change $^{4}$ & unit & 58 & $4.36(-0.97-11.29)$ \\
\hline BMI $^{6}$ Change ${ }^{4}$ & $\mathrm{~kg} /$ height in $\mathrm{m}^{2}$ & 73 & $-0.76(-1.36-0.03)$ \\
\hline Albumin Change $^{4}$ & $g / L$ & 54 & $0.6(0.2-0.9)$ \\
\hline
\end{tabular}

${ }^{1}$ Number of patients, ${ }^{2}$ Median, ${ }^{3}$ Interquartile range, ${ }^{4}$ From treatment start to followup (3 months), ${ }^{5}$ Geriatric Nutritional Risk Index, ${ }^{6}$ Body Mass Index lost to follow-up (2 patients). Table 2 further describes clinical variables associated with swallowing function, interventions and outcomes of those patients on the study. While $65.3 \%$ took a spectrum of oral nutrition at completion of CRT, $59.2 \%$ of patients were found with aspiration by FEES or CT scan. $28 \%$ of patients were hospitalized during or after treatment for management of CRT-associated complications.

\section{Longitudinal evaluation of nutritional indices}

Longitudinal changes in patient BMI, GNRI, weight and albumin are shown in Figure 2. The median weight change from treatment initiation to treatment completion was $-11 \%(-17.2$ $\mathrm{lb}, \mathrm{IQR},-28.6$ to $-9.5 \mathrm{lbs}$ ), with a $9 \%$ decrease in BMI, both of which were most significant following treatment completion. Median and mean weights of the cohort changed modestly over time and plateaued at three months. Change in serum albumin appeared to be the most sensitive to changes in nutritional status. Composite indices such as BMI and GNRI had smaller fluctuations across the treatment and post- treatment interval.

\section{Predictors of delayed ppeg tube removal}

A univariate cox proportional hazards analysis (Table 3) demonstrated that treatment site (base of tongue vs. other) (HR $0.76,95 \%$ CI $0.45-1.28, \mathrm{p}=0.192)$, mucositis grade $(3-4$ vs. 1-2) (HR 0.79, 95\% CI 0.49-1.30, p = 0.201), presence of documented aspiration (HR 0.24, 95\% CI 0.11-0.53, p < 0.001), documented presence of vallecula residue (HR 0.56, 95\% CI $0.34-0.92, p=0.02$ ), and weight loss during treatment (HR 0.98, 95\% CI 0.961-1.000, p = 0.055) were factors that decreased the probability of pPEG tube removal $(\mathrm{p}<0.2)$ (Table 4).

Radiotherapy dose, delivery technique, and chemotherapy type did not impact pPEG tube duration. After adjusting for patient- and treatment-related factors, increasing mucositis grade (3-4 vs. 1-2) (HR 0.55, 95\% CI 0.32-0.95, p = 0.03) and clinical stage ([IV B, C vs III, IVA]; 3-4 vs. 1-2) (HR 0.36, 95\% CI $0.15-0.91, p=0.03)$ remained statistically significant in the multivariate model (Table 4). Weight change during treatment lost significance in the final model (HR 0.98, 95\% CI 0.96-1.0, $\mathrm{p}=0.187)$.

\section{Discussion}

Timing of supplemental enteral nutrition in the management of patients with OPC remains controversial, with institutional preference often driving pPEG versus reactive $G$ tube placement. Our institutional practice is to recommend PEG tubes prophylactically in all patients who undergo definitive CRT. Some centers selectively place gastrostomy tubes in patients at high risk based on anatomic [18] nutritional status [19] or pre-existing swallowing impairment. Others believe that elective enteral feeding may compromise longterm swallowing function via disuse [20] or that the risks of complications related to placing pPEG tubes outweigh their benefits [21]. Recognizing modifiable patient characteristics that may prolong PEG tube dependence may help to identify at-risk patients in the pre-treatment stage; providing an 


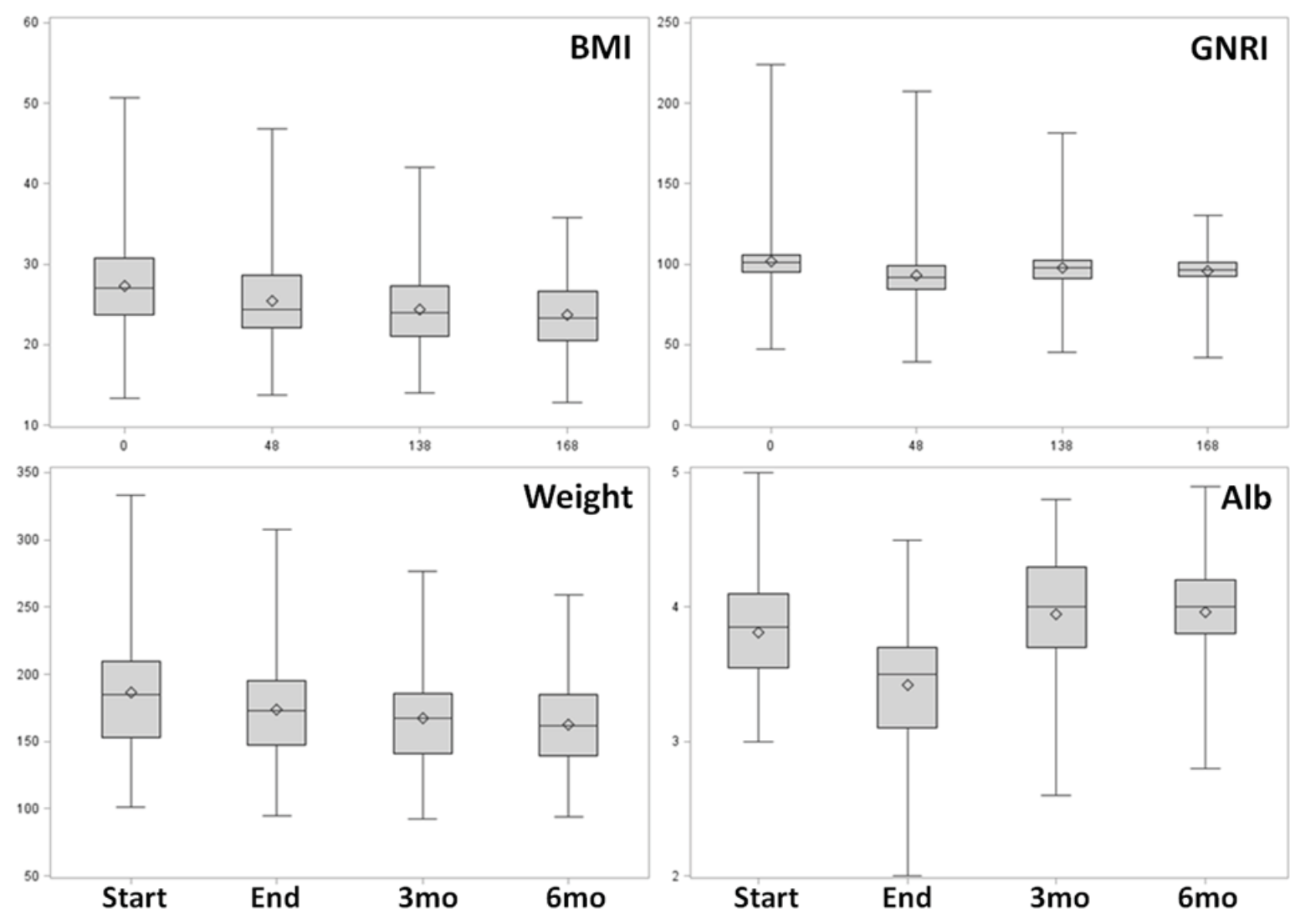

Figure 2: Longitudinal Nutritional Indices.

Start = Concurrent CRT treatment initiation, end = Concurrent CRT treatment completion, $3 \mathrm{mo}=3$ months following CRT treatment completion, and $6 \mathrm{mo}=6$ months following CRT treatment completion. Body Mass Index (BMI)(pounds/meter ${ }^{2}$ ), Albumin (grams/dL), Geriatric Nutritional Risk Index (GNRI), Weight (pounds).

opportunity for early intervention through prophylactic pain management or aggressive speech and swallow therapy.

Our 1 year PEG tube dependence was $15.1 \%$ while Setton, et al. (2015) showed 1 year dependence rate of $8.6 \%$ [14]. As mentioned previously, their study showed that cytotoxic chemotherapy administration was predictive of PEG tube dependence based on both univariate and multivariate analyses. These findings correlate with our higher rate of PEG tube dependence, as $100 \%$ of the patients in our study population underwent concurrent CRT. In the prior study, only $65.2 \%$ received cytotoxic chemotherapy, with the remainder receiving radiation therapy only [14]. Treatment-related adverse effects of chemotherapy (nausea, vomiting, anorexia) accentuate malnutrition, likely leading to greater PEG dependence.

Advanced stage $\mathrm{T} 3 / 4$ disease has been noted to prolong PEG tube dependence [22]. Similarly, we found that patients with advanced stages (IV B and C) experienced prolonged time to pPEG tube removal and influence of disease stage was maintained after adjusting for other potential covariates (HR $0.36,95 \%$ CI $0.15-0.91, \mathrm{p}=0.030$ ). The influence of primary site location was also significant in predicting PEG dependence. placement. Similarly, studies that identified the oropharynx as an at-risk subsite often had more patients with disease subsites at the base of the tongue [18]. In our cohort, patients with primary disease at the base of the tongue had a median time to pPEG tube removal of 187 days (95\% CI 120-
249) vs. 123 days for other subsites (95\% CI 80-150; $\mathrm{p}=0.18$ ). This is likely because a significant amount of the pharynx is involved in the treatment field, and dysphagia is more common in this tumor location. Although the primary site of disease met the criteria in our univariate analysis for inclusion into the multivariate analysis, primary site became borderline significant after adjusting for other influential covariates (HR $0.58,95 \%$ CI $0.33-1.01, \mathrm{p}=0.052$ ).

Treatment-related adverse effects including mucositis, xerostomia, dysphagia, and dysgeusia commonly exacerbate malnutrition. Grade 3 or worse mucositis have been reported to develop in about $50 \%$ of patients undergoing concurrent CRT, similar to our findings, where grade 3-4 mucositis occurred in $52.6 \%$ of the cohort $[4,17,23]$. These patients experience a longer time to pPEG tube removal compared with patients experiencing grade 1-2 mucositis $(p=0.2)$. After adjusting for other patient- and treatment-related factors, the grade of mucositis was statistically significant (HR 0.55, (95\% CI 0.32$0.95, \mathrm{p}=0.030$ ). The resultant pain and inflammation is a wellknown contributor to treatment-related anorexia and resultant nutritional decline [24]. Prophylactic pain management may facilitate early nutritional recovery.

HPV-positive patients may be more susceptible to treatment-related insult, thus increasing risk of pPEG tube dependency [25]. Tobacco use may reduce mucosal sensitivity, and thus may reduce the incidence of PPEG tube dependence 
[25]. It has previously been shown that HPV positivity as well as non-smoking status are associated with an increased frequency of high grade mucositis among patients with OPC undergoing definitive CRT, but neither had a statistically significant impact on pPEG tube duration [26]. Similarly, in the current cohort neither HPV status nor tobacco use were associated with delayed pPEG tube removal.

Dysphagia from tumor effects and CRT therapy lead to aspiration, and is another major contributing factor to malnourishment and hospital stays [6]. The presence of documented aspiration (to any degree) significantly increased

Table 3: Predictors of pPEG Tube Duration - Univariate Analysis.

\begin{tabular}{|c|c|c|c|c|}
\hline & & $\mathbf{N}$ & $\mathrm{HR}^{1}\left(95 \% \mathrm{Cl}^{2}\right)$ & p-Value \\
\hline Age & Years & 75 & $0.99(0.96,1.02)$ & 0.59 \\
\hline Sex & $\begin{array}{c}\text { Female } \\
\text { Male }\end{array}$ & $\begin{array}{l}12 \\
63\end{array}$ & $\begin{array}{c}1.36(0.69,2.68) \\
\text { ref }\end{array}$ & 0.38 \\
\hline Race & $\begin{array}{l}A A^{3} \\
\text { White }\end{array}$ & $\begin{array}{l}11 \\
64\end{array}$ & $\begin{array}{c}0.99(0.49,2.01) \\
\text { ref }\end{array}$ & 0.99 \\
\hline Anatomic Site & $\begin{array}{c}\text { Tongue Base } \\
\text { Other }\end{array}$ & $\begin{array}{l}25 \\
50\end{array}$ & $\begin{array}{c}0.76(0.45,1.28) \\
\text { ref }\end{array}$ & 0.19 \\
\hline N Stage & $\begin{array}{l}\text { N2b-N3 } \\
\text { NO-2a }\end{array}$ & $\begin{array}{l}62 \\
13\end{array}$ & $\begin{array}{c}1.57(0.82,3.03) \\
\text { ref }\end{array}$ & 0.17 \\
\hline M Stage & $\begin{array}{l}\text { M1 } \\
\text { M0 }\end{array}$ & $\begin{array}{c}3 \\
72\end{array}$ & $\begin{array}{c}1.06(0.26,4.38) \\
\text { ref }\end{array}$ & 0.93 \\
\hline TNM Stage & $\begin{array}{l}\text { IVB-C } \\
\text { III-IVA }\end{array}$ & $\begin{array}{l}10 \\
65\end{array}$ & $\begin{array}{c}0.42(0.18,0.99) \\
\text { ref }\end{array}$ & 0.47 \\
\hline HPV Status & $\begin{array}{l}\text { Positive } \\
\text { Negative }\end{array}$ & $\begin{array}{l}57 \\
18\end{array}$ & $\begin{array}{c}1.16(0.66,2.04) \\
\text { ref }\end{array}$ & 0.62 \\
\hline Alcohol Use & $\begin{array}{c}\text { Active } \\
\text { Occasional/Never }\end{array}$ & $\begin{array}{l}28 \\
47\end{array}$ & $\begin{array}{c}0.85(0.51,1.43) \\
\text { ref }\end{array}$ & 0.55 \\
\hline Smoking & $\begin{array}{c}\text { Active/Former } \\
\text { Never }\end{array}$ & $\begin{array}{l}31 \\
44\end{array}$ & $\begin{array}{c}1.02(0.62,1.67) \\
\text { ref }\end{array}$ & 0.94 \\
\hline IMRT Used & $\begin{array}{l}\text { Yes } \\
\text { No }\end{array}$ & $\begin{array}{l}61 \\
14\end{array}$ & $\begin{array}{c}1.10(0.59,2.07) \\
\text { ref }\end{array}$ & 0.76 \\
\hline Mucositis Grade & $\begin{array}{l}\text { Grade 3-4 } \\
\text { Grade 1-2 }\end{array}$ & $\begin{array}{l}39 \\
36\end{array}$ & $\begin{array}{c}0.79(0.49,1.30) \\
\text { ref }\end{array}$ & 0.20 \\
\hline $\begin{array}{l}\text { Excessive Mucous } \\
\text { Production }\end{array}$ & $\begin{array}{l}\text { Yes } \\
\text { No }\end{array}$ & $\begin{array}{l}56 \\
19\end{array}$ & $\begin{array}{c}1.19(0.67,2.12) \\
\text { ref }\end{array}$ & 0.55 \\
\hline Vallecula Penetration & $\begin{array}{l}\text { Absent } \\
\text { Present }\end{array}$ & $\begin{array}{l}26 \\
49\end{array}$ & $\begin{array}{c}0.56(0.34,0.92) \\
\text { ref }\end{array}$ & 0.02 \\
\hline Aspiration & $\begin{array}{l}\text { Yes } \\
\text { No }\end{array}$ & $\begin{array}{l}44 \\
31\end{array}$ & $\begin{array}{c}0.24(0.11,0.53) \\
\text { ref }\end{array}$ & $<0.001$ \\
\hline $\begin{array}{l}\text { Received Dysphagia } \\
\text { Treatment }\end{array}$ & $\begin{array}{l}\text { Yes } \\
\text { No }\end{array}$ & $\begin{array}{l}46 \\
29\end{array}$ & $\begin{array}{c}0.78(0.47,1.28) \\
\text { ref }\end{array}$ & 0.32 \\
\hline $\begin{array}{l}\text { Oral Intake } \\
\text { at Treatment } \\
\text { Completion }\end{array}$ & $\begin{array}{l}\text { Yes } \\
\text { No }\end{array}$ & $\begin{array}{l}49 \\
26\end{array}$ & $\begin{array}{c}1.50(0.89,2.50) \\
\text { ref }\end{array}$ & 0.12 \\
\hline Weight Change ${ }^{4}$ & Ibs & 73 & $0.98(0.96,1.00)$ & 0.055 \\
\hline GNRI $^{5}$ Change ${ }^{4}$ & unit & 62 & $1.01(0.97,1.05)$ & 0.60 \\
\hline BMI $^{6}$ Change $^{4}$ & $\mathrm{~kg} /$ height in $\mathrm{m}^{2}$ & 73 & $0.89(0.74,1.08)$ & 0.24 \\
\hline Albumin Change $^{4}$ & $g / L$ & 58 & $1.06(0.61,1.81)$ & 0.85 \\
\hline
\end{tabular}

${ }^{1}$ Hazard Ratio, ${ }^{2}$ Confidence interval, ${ }^{3}$ African American, ${ }^{4}$ From treatment start to follow-up (3 months), ${ }^{5}$ Geriatric Nutritional Risk Index, ${ }^{6}{ }^{6}$ Body Mass Index, ref $=$ referent group
Table 4: Predictors of pPEG Tube Duration - Multivariate Model.

\begin{tabular}{|c|c|c|c|c|}
\hline & & $\mathbf{N}$ & $\operatorname{HR}^{1}\left(95 \% \mathrm{Cl}^{2}\right)$ & p-Value \\
\hline Mucositis Grade & $\begin{array}{l}\text { Grade 3-4 } \\
\text { Grade 1-2 }\end{array}$ & $\begin{array}{l}39 \\
36\end{array}$ & $\begin{array}{c}0.55(0.32,0.95) \\
\text { ref }\end{array}$ & 0.030 \\
\hline TNM Stage & $\begin{array}{l}\text { IVB-C } \\
\text { III-IVA }\end{array}$ & $\begin{array}{l}10 \\
65\end{array}$ & $\begin{array}{c}0.36(0.15,0.91) \\
\text { ref }\end{array}$ & 0.030 \\
\hline Primary Site & $\begin{array}{c}\text { Tongue Base } \\
\text { Other }\end{array}$ & $\begin{array}{l}25 \\
50\end{array}$ & $\begin{array}{c}0.58(0.33,1.01) \\
\text { ref }\end{array}$ & 0.052 \\
\hline Aspiration & $\begin{array}{l}\text { Yes } \\
\text { No }\end{array}$ & $\begin{array}{l}45 \\
31\end{array}$ & $\begin{array}{c}0.61(0.36,1.04) \\
\text { ref }\end{array}$ & 0.067 \\
\hline Weight Change ${ }^{3}$ & lbs & 73 & $0.98(.96,1.0)$ & 0.19 \\
\hline
\end{tabular}

${ }^{1}$ Hazard Ratio, ${ }^{2}$ Confidence interval, ${ }^{3}$ Weight Change from Treatment Start to $1^{\text {st }}$ Follow-up at 3 months, ref $=$ referent group

the time to $\mathrm{pPEG}$ tube removal $(\mathrm{p}<0.001)$. Aspiration remained significant in the multivariate model after adjusting for other influential covariates (HR 0.61, 95\% CI 0.36-1.04, p = 0.067). A study showed It was reported that if unconstrained during treatment planning, increased radiation dose to the pharyngeal constrictors, glottis, and supraglottic larynx can lead to long-term dysphagia and aspiration [3]. Furthermore, they showed that advanced planning with use of IMRT to constrain oropharyngeal structures can improve swallowing and eating. Patients in our study were treated without a constrictor/ swallowing structure-sparing approach and as a result, our study population may have been more prone to radiationrelated swallowing dysfunction.

The most significant change in weight and BMI was noted following treatment completion ( $11 \%$ and $9 \%$, respectively), with the nutritional decrement plateauing after three months. Similarly, other groups have noted a median percent weight loss of $2.9-10 \%$ in patients with OPC with PEG tube placement [19]. Weight change was only borderline significant after adjusting for other patient- and treatment- related factors $(\mathrm{p}=0.190)$, and significance was lost in the multivariate analysis. This suggests that while nutritional factors often drive early usage and need for pPEG tubes, other factors such as swallowing dysfunction are more likely to drive pPEG dependence.

Although this study is limited by size and retrospective design, however, this design allowed for a greater sample size to study a population in which $100 \%$ undergo CRT and pPEG placement. Additional limitations include heterogeneity in disease stage and extent of disease, which can significantly alter the pretreatment swallowing profile. Additionally, there was inconsistent use of IMRT or 3DCRT, the variety and exposure of which may impact dose distributions to swallowing muscles and thus, long-term function ${ }^{3}$. Despite this, a number of strong influential factors (mucositis grade, advanced TNM stage, and primary site) have substantial impact on delayed pPEG removal. Recognition of these factors warrant continued study to identify potential subpopulations that may benefit from early intervention.

Per institution protocol, patients undergoing CRT have an early initiation of consistent swallowing evaluations and exercises during treatment. More than half $(65.3 \%)$ of patients were on a spectrum of oral intake at the end of treatment. Our 3month pPEG tube dependence rate was $59.2 \%$. These results 
are similar to other published series of OPC patients that documented 3 month pPEG tube dependence rates of 51\% [27]. While we routinely recommend that patients receive aggressive speech and swallow therapy to prevent persistent dysphagia, this study did not show that it was significantly associated with decreased PEG tube dependence. However, the aim of this study was to retrospectively evaluate factors associated with pPEG tube dependence, and further randomized control trials would be necessary to evaluate the potential efficacy of aggressive speech and swallow therapy in reducing pPEG tube dependence.

\section{Conclusion}

Advanced disease stage, tumor location (tongue base), grade 3-4 mucositis, and presence of aspiration influenced time to pPEG tube removal. Our high rates of pPEG tube dependence likely correlate with the study population's advanced tumor stage and use of concurrent chemoradiotherapy. Patients identified with these risk factors should be rigorously evaluated for intensive early swallowing and supportive care interventions. Further studies are necessary to clearly evaluate and treat modifiable factors.

\section{Acknowledgements}

The authors also wish to thank Bonny E. Morris for editorial support.

\section{Funding sources}

The authors wish to acknowledge the support of the "Biostatistics Shared Resource," Comprehensive Cancer Center of Wake Forest University and NCI Cancer Center Support Grant P30 CA012197.

\section{References}

1. Beaver ME, Matheny KE, Roberts DB, Myers JN (2001) Predictors of weight loss during radiation therapy. Otolaryngology-Head and Neck Surgery 125 : 645-648. Link: https://bit.ly/3jcVQBB

2. Nugent B, Lewis S, O'Sullivan JM (2013) Enteral feeding methods for nutritional management in patients with head and neck cancers being treated with radiotherapy and/or chemotherapy. Cochrane Database Syst Rev 20. Link: https://bit.ly/37INhC6

3. Eisbruch A, Schwartz M, Rasch C, Vineberg K, Damen E, et al. (2004) Dysphagia and aspiration after chemoradiotherapy for head-and-neck cancer: which anatomic structures are affected and can they be spared by IMRT? Int J Radiat Oncol Biol Phys 60: 1425-1439. Link: https://bit.ly/31/2uiO

4. Romesser PB, Romanyshyn JC, Schupak KD, Setton J, Riaz N, et al. (2012) Percutaneous Endoscopic Gastrostomy in Oropharyngeal Cance Patients Treated With Intensity-Modulated Radiotherapy With Concurrent Chemotherapy. Cancer 118: 6072-6078. Link: https://bit.ly/37otcuT

5. Beer KT, Krause KB, Zuercher T, Stanga Z (2005) Early percutaneous endoscopic gastrostomy insertion maintains nutritional state in patients with aerodigestive tract cancer. Nutr Cancer 52: 29-34. Link: https://bit.ly/37ky6cs

6. Lee JH, Machtay M, Unger LD, Weinstein GS, Weber RS, et al. (1998) Prophylactic gastrostomy tubes in patients undergoing intensive irradiation for cancer of the head and neck. Arch Otolaryngol Head Neck Surg 124: 871875. Link: https://bit.ly/3481Rep
7. Nugent B, Parker MJ, McIntyre IA (2010) Nasogastric tube feeding and percutaneous endoscopic gastrostomy tube feeding in patients with head and neck cancer. J Hum Nutr Diet 23: 277-284. Link: https://bit.ly/31oohqa

8. Locher JL, Bonner JA, Carroll WR, Caudell JJ, Keith JN, et al. (2011) Prophylactic Percutaneous Endoscopic Gastrostomy Tube Placement in Treatment of Head and Neck Cancer: A Comprehensive Review and Call for Evidence-Based Medicine. JPEN J Parenter Enteral Nutr 35: 365-374. Link: https://bit.ly/3kbNb3J

9. Mekhail TM, Adelstein DJ, Rybicki LA, Larto MA, Saxton JP, et al. (2001) Enteral nutrition during the treatment of head and neck carcinoma - Is a percutaneous endoscopic gastrostomy tube preferable to a nasogastric tube? Cancer 91 1785-1790. Link: https://bit.ly/31hGsgT

10. Assenat E, Thezenas S, Flori N, Pere-Charlier N, Garrel R, et al. (2011) Prophylactic Percutaneous Endoscopic Gastrostomy in Patients With Advanced Head and Neck Tumors Treated by Combined Chemoradiotherapy. J Pain Symptom Manage 42: 548-556. Link: https://bit.ly/37jbngT

11. Grant DG, Bradley PT, Pothier DD, Bailey D, Caldera S, et al. (2009) Complication following gastrostomy tube insertion in patients with head and neck cancer: a prospective multi-institution study, systematic review and meta-analysis. Clin Otolaryngol 34: 103-112. Link: https://bit.ly/3kdMAOH

12. Langmore S, Krisciunas GP, Miloro KV, Evans SR, Cheng DM (2012) Does PEG use cause dysphagia in head and neck cancer patients? Dysphagia 27: 251259. Link: https://bit.ly/3dIEAmr

13. Yang W, McNutt TR, Dudley SA, Kumar R, Starmer HM, et al. (2016) Predictive Factors for Prophylactic Percutaneous Endoscopic Gastrostomy (PEG) Tube Placement and Use in Head and Neck Patients Following Intensity-Modulated Radiation Therapy (IMRT) Treatment: Concordance, Discrepancies, and the Role of Gabapentin. Dysphagia 31: 206-213. Link: https://bit.ly/2T7YAFS

14. Setton J, Lee NY, Riaz N, Huang SH, Waldron J, et al. (2015) A multiinstitution pooled analysis of gastrostomy tube dependence in patients with oropharyngeal cancer treated with definitive intensity-modulated radiotherapy. Cancer 121: 294-301. Link: https://bit.ly/3dEnrKy

15. de Roda Husman AM, Walboomers JM, van den Brule AJ, Meijer CJ, Snijders PJ (1995) The use of general primers GP5 and GP6 elongated at their 3' ends with adjacent highly conserved sequences improves human papillomavirus detection by PCR. J Gen Virol 76: 1057-1062. Link: https://bit.ly/2HfRtJ1

16. Nobre RJ, de Almeida LP, Martins TC (2008) Complete genotyping of mucosa human papillomavirus using a restriction fragment length polymorphism analysis and an original typing algorithm. J Clin Virol 42: 13-21. Link: https://bit.ly/31mUVIG

17. Bouillanne O, Morineau G, Dupont C, Coulombel I, Vincent JP, et al. (2005) Geriatric Nutritional Risk Index: a new index for evaluating at-risk elderly medical patients. Am J Clin Nutr 82: 777-783. Link: https://bit.ly/2IEEwsp

18. Zauls AJ, Watkins JM, Lucas J, Shirai K, Sharma AK (2013) Requirement of percutaneous endoscopic gastrostomy tube placement in head-and-neck cancer treated with definitive concurrent chemoradiation therapy: An analysis of clinical and anatomic factors. Practical Radiation Oncology 3: e61-e69. Link: https://bit.ly/3o5oTuA

19. Piquet MA, Ozsahin M, Larpin I, Zouhair A, Coti P, et al. (2002) Early nutritional intervention in oropharyngeal cancer patients undergoing radiotherapy. Support Care Cancer 10: 502-504. Link: https://bit.ly/3kbOqjp

20. Carnaby-Mann G, Crary MA, Schmalfuss I, Amdur R (2012) "Pharyngocise": randomized controlled trial of preventative exercises to maintain muscle structure and swallowing function during head-and-neck chemoradiotherapy. Int J Radiat Oncol Biol Phys 83: 210-219. Link: https://bit.ly/3kcYBUP

21. Schneider AS, Schettler A, Markowski A, Luettig B, Kaufmann B, et al. (2014) Complication and mortality rate after percutaneous endoscopic gastrostomy are low and indication-dependent. Scand J Gastroenterol 49: 891-898. Link: https://bit.ly/35aSOUC 
22. Salas S, Baumstarck-Barrau K, Alfonsi M, et al. (2009) Impact of the prophylactic gastrostomy for unresectable squamous cell head and neck carcinomas treated with radio-chemotherapy on quality of life: Prospective randomized trial. Radiother Oncol 93: 503-509. Link: https://bit.ly/37kfRnp

23. Nguyen NP, North D, Smith HJ, Dutta S, Alfieri A, et al. (2006) Safety and effectiveness of prophylactic gastrostomy tubes for head and neck cancer patients undergoing chemoradiation. Surg Oncol 15: 199-203. Link: https://bit.ly/35ag9uh

24. Guney Y, Ozel Turkcu U, Hicsonmez A, Nalca Andrieu M, Kurtman C (2007) Ghrelin may reduce radiation-induced mucositis and anorexia in head-neck cancer. Med Hypotheses 68: 538-540. Link: https://bit.ly/31kgA4d

25. Vatca M, Lucas JT, Laudadio J, D'Agostino RB, Waltonen JD, et al. (2014) Retrospective analysis of the impact of HPV status and smoking on mucositis in patients with oropharyngeal squamous cell carcinoma treated with concurrent chemotherapy and radiotherapy. Oral Oncol 50: 869-876. Link: https://bit.ly/3m019sd

26. Strom T, Trotti AM, Kish J, Rao NG, McCaffrey J, et al. (2013) Risk factors for percutaneous endoscopic gastrostomy tube placement during chemoradiotherapy for oropharyngeal cancer. JAMA Otolaryngol Head Neck Surg 139: 1242-1246. Link: https://bit.ly/34chLV8

27. McBride SM, Parambi RJ, Jang JW, Goldsmith T, Busse PM, et al. (2014) Intensity-modulated versus conventional radiation therapy for oropharyngeal carcinoma: long-term dysphagia and tumor control outcomes. Head \& Neck 36: 492-498. Link: https://bit.ly/31/5yLQ

\section{Discover a bigger Impact and Visibility of your article publication with}

\section{Peertechz Publications}

\section{Highlights}

* Signatory publisher of ORCID

- Signatory Publisher of DORA (San Francisco Declaration on Research Assessment)

- Articles archived in worlds' renowned service providers such as Portico, CNKI, AGRIS, TDNet, Base (Bielefeld University Library), CrossRef, Scilit, J-Gate etc.

* Journals indexed in ICMJE, SHERPA/ROMEO, Google Scholar etc.

- OAI-PMH (Open Archives Initiative Protocol for Metadata Harvesting)

* Dedicated Editorial Board for every journal

* Accurate and rapid peer-review process

* Increased citations of published articles through promotions

* Reduced timeline for article publication

Submit your articles and experience a new surge in publication services (https://www.peertechz.com/submission).

Peertechz journals wishes everlasting success in your every endeavours.

Copyright: @ 2020 Lucas JT, et al. This is an open-access article distributed under the terms of the Creative Commons Attribution License, which permits unrestricted use distribution, and reproduction in any medium, provided the original author and source are credited. 